\title{
Port side tubercular abscess in women after lap-diagnosis for infertility
}

\author{
Sangeeta Arya ${ }^{1}$, Anil Verma ${ }^{2}$, Kiran Pandey ${ }^{1}$, Preeti Yadav ${ }^{1}$, Asmita Singh $^{1}$ \\ ${ }^{1}$ Department of Obstetrics \& Gynaecology, GSVM Medical College Kanpur, Uttar Pradesh, India \\ ${ }^{2}$ Department of Anaesthesia, GSVM Medical College Kanpur, Uttar Pradesh, India \\ Received: 28 October 2014 \\ Accepted: 10 November 2014 \\ *Correspondence: \\ Dr. Sangeeta Arya, \\ E-mail: asmitasingh506@gmail.com \\ Copyright: ( $)$ the author(s), publisher and licensee Medip Academy. This is an open-access article distributed under \\ the terms of the Creative Commons Attribution Non-Commercial License, which permits unrestricted non-commercial \\ use, distribution, and reproduction in any medium, provided the original work is properly cited.
}

\begin{abstract}
Infertility whether primary or secondary is an emotional and financial burden to the concerned family. In India we occasionally deal with financial constraints of the women undergoing treatment for infertility. Women getting post procedure port site tubercular abscess further makes the situation worse leading to long term burden of drug intake which could have been avoided by proper knowledge and use of sterilization technique of laparoscopic instruments.
\end{abstract}

Keywords: Port site, Tubercular abscess, Lap diagnosis, Infertility

\section{INTRODUCTION}

Infertility in our scenario is still considered as a social stigma causing mental harassment and financial burden on the concerned couple requiring multiple visits to the doctor with a battery o tests. Laparoscopy is an important tool for surgical evaluation of women suffering from infertility after being gone through some basic investigations as it is a costly and invasive procedure. It helps in evaluating pelvic conditions along with various fertility enhancing surgeries like adhesiolysis etc.

All the women undergoing this procedure are investigated properly and usually discharged on the same day. Complications of this procedure include injury to bladder, ureter, bowel and blood vessels including port side skin infection despite anaesthesia complications.

\section{CASE REPORT}

A 24 years old female had undergone lap diagnosis with chromopertubation. An umbilical main port was made and two accessory ports were made at suprapubic area and in left side of lower abdomen. Peroperatively intraperitoneal conditions were within normal limits and both tubes were patent. She was discharged on the same day in the evening and was asked to come on $8^{\text {th }}$ postoperative day for stitch removal. But on fifth day she came in OPD with complaint of soakage of dressing present at accessory port on left side of abdomen. The site was seen, slight serous discharge was seen. It was cleaned by spirit, redressing was done and she was put on oral cefixime $200 \mathrm{mg} \mathrm{BD}$ for five days.

Again she came on eighth post-operative day with discomfort at the same site with increased soakage around the wound. When the incision site was opened a punched out lesion was seen. Taking the clinical sign of tubercular ulcers in mind the local curettage was done and tissue was sent for histopathology and PCR for tuberculosis.

The histopathology showed granulation tissue suggestive of tuberculosis. Antitubercular treatment with four drug regime (rifampicin, Isoniazid, ethambutol and pyrazinamide) was started and was given for two months and two drug regime (Rifampicin and isoniazid) for rest four months. She responded well after two months and the scar healed by secondary intention. 


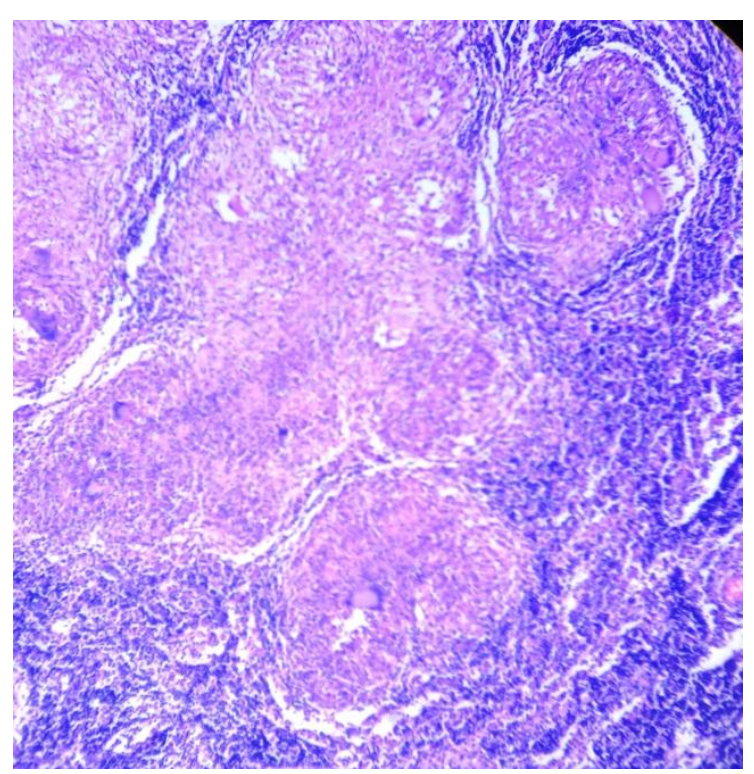

Figure 1: Histopathology shows granulation tissue suggestive of tuberculosis.

\section{DISCUSSION}

In our clinical practice, the aim of laparoscopic surgery was to enhance the cosmetic outlook of surgical field, lessen the post-operative pain and duration of hospital stay so as to bring about reduction in magnitude of convalescence. All of these are served with smaller incision of key hole surgery, but when these tiny incisions get cursed with infections with a dragging and indolent course, the entire purpose of decreasing morbidity goes into vain.

In India TB remains the major health problem with 1.8 million new cases of TB detected every year of which one-fifth are extra-pulmonary. ${ }^{1}$ Till now it has been noted that port site TB is usually due to the improper sterilization of the laparoscopic instruments and only one case report is published which has attributed port site TB to an endogenous source. ${ }^{2}$

Port site TB has been reported following laparoscopic cholecystectomy. ${ }^{3,4}$ appendicectomy ${ }^{5}$ and per-cutaneous nephrolithotripsy. ${ }^{6}$ However, port-site tuberculosis following diagnostic laparoscopy has not been reported.

Ramesh et al reported eight patients with biopsy-proven tuberculosis at the port site unassociated with other clinical features of tuberculosis following cholecystectomy. ${ }^{4}$ Three of the eight patients had positive culture for Mycobacterium tuberculosis. Jagadish et al. reported one such case. ${ }^{7}$ Bhandarkar et al. reported a 14year-old girl who developed port-site infection with Mycobacterium chelonei following laparoscopic appendicectomy. ${ }^{5}$ She was treated with local exploration and excision of sinuses, followed by antitubercular treatment for six months.
The most common practice of instrument "sterilization" in India and many parts of the developed and developing world has been to immerse instruments in $2 \%$ alkaline glutaraldehyde for $20 \mathrm{~min}^{8}$ Although sterilization is defined as "the complete elimination of all forms of microbial life", it is now widely agreed that $2 \%$ glutaraldehyde achieves high-level disinfection and not sterilization. This has been further reinforced by Griffiths et al., who have highlighted the failure of a $20-\mathrm{min}$ instrument soak in $2 \%$ alkaline glutaraldehyde to sterilize instruments. ${ }^{10}$ In another study, mycobacterium TB was present in one of five scopes after even after 45-min exposure. $^{11}$

In India where cost is a great restrainer, the use of all new disposable items for an endoscopic procedure makes the cost of the procedure exuberant. Hence here we try to strike a balance between the safety of the procedure, and the cost of the procedure so as not to make it unaffordable for the common patients. This is achieved by re-sterilization of the disposable reusable material. Since there are no definitive guidelines available, we rely on the literature available for the other specialty for the sterilization of our reusable items. ${ }^{8}$

To conclude, awareness of this ubiquitous opportunistic organism which is difficult to be eradicated from hospital environment, careful surveillance, detailed attention to disinfection method of medical devices and appropriate control measures are needed to prevent this potentially frustrating complication.

Funding: No funding sources

Conflict of interest: None declared

Ethical approval: Not required

\section{REFERENCES}

1. Chauhan LS, Tonsing J. Revised national TB control programme in India. Tuberculosis (Edinb). 2005;85:271-6.

2. Cunnigaiper ND, Venkatraman S. Port site tuberculosis: Endogenous or exogenous infection? Surg Infect (Larchmrt). 2010;11:77-8.

3. Tauro LF, Satish RB, Matris JJ, Divakar HS. Port site tuberculosis: a rare complication following laparoscopic cholecystectomy. Indian J Surg. 2005;67:104-5.

4. Ramesh H, Prakash K, Lekha V, Jacob G, Venugopal A, Venugopal B. Port-site tuberculosis after laparoscopy: Report of eight cases. Surg Endosc. 2003;17:930-2.

5. Bhandarkar DS, Bhagwat S, Punjani R. Port-site infection with Mycobacterium chelonei following laparoscopic appendicectomy. Indian J Gastroenterol. 2001;20:247-8.

6. Rahul Gupta, Arati Mahajan, Chaman Gupta. Post per-cutaneous nephrolithotripsy nephrostomy site tuberculosis: a report of 6 cases. Urol Ann. 2012 JanApr;4(1):41-4. 
7. Jagadish N, Sameer R, Omprakash R. Port-site tuberculosis: a rare complication following laparoscopic cholecystectomy. Scand J Infect Dis. 2002;34:928-9.

8. Rutala WA, Clontz EP, Weber DJ, Hoffmann KK. Disinfection practices for endoscopes and other semi critical items. Infect Control Hosp Epidemiol. 1991;12:282-8.

9. Rutala WA. Disinfection, sterilization, and waste disposal. In: Wenzel RP, eds. Prevention and Control of Nosocomial Infections. 2nd ed. Baltimore, MD: Williams and Wilkins; 1997: 539-594.
10. Griffiths PA, Babb JR, Bradley CR, Fraise AP. Glutaraldehyde-resistant Mycobacterium chelonae from endoscope washer disinfectors. J Appl Microbiol. 1997;82:519-26.

11. Urayama S, Kozarek RA, Sumida S, Raltz S, Merriam L, Pethigal P. Mycobacteria and glutaraldehyde: is high-level disinfection of endoscopes possible? Gastrointest Endosc. 1996;43:451-6.

DOI: 10.5455/2320-1770.ijrcog20141243

Cite this article as: Arya S, Verma A, Pandey K, Yadav P, Singh A. Port side tubercular abscess in women after lap-diagnosis for infertility. Int J Reprod Contracept Obstet Gynecol 2014;3:1097-9. 